Frey S, Herbst P \& Walter A (2014) Measuring mutual fund herding - A structural approach, Journal of International

Financial Markets, Institutions and Money, 32, pp. 219-239.

This is the peer reviewed version of this article

NOTICE: this is the author's version of a work that was accepted for publication in Journal of International Financial Markets, Institutions and Money. Changes resulting from the publishing process, such as peer review, editing, corrections, structural formatting, and other quality control mechanisms may not be reflected in this document. Changes may have been made to this work since it was submitted for publication. A definitive version was subsequently published in Journal of International Financial Markets, Institutions and Money, [VOL 32 (2014)] DOI: http://dx.doi.org/10.1016/j.intfin.2014.05.006 


\title{
Measuring Mutual Fund Herding - A Structural Approach*
}

\author{
Stefan Frey ${ }^{\dagger}$ \\ Leibniz University Hannover and CFR Cologne \\ Patrick Herbst ${ }^{\ddagger}$ \\ Andreas Walter ${ }^{\S}$ \\ Justus-Liebig-University Giessen
}

\begin{abstract}
This paper proposes a methodological improvement to empirical studies of herd behavior based on investor transactions. By developing a simple model of trading behavior, we show that the traditionally used herding measure produces biased results. As this bias depends on characteristics of the data, it also affects the robustness of previous findings. We derive a new measure that is unbiased and shows superior statistical properties for data sets commonly used. In an analysis of the German mutual fund market, our measure provides new insights into fund manager herding that would have been undetected under the traditional statistic.
\end{abstract}

Keywords: Herding, LSV measure, mutual funds

JEL classification: G11, G14, G23

*We owe thanks to Joachim Grammig, Alexander Kempf, Marno Verbeek as well as conference and seminar participants in Erfurt, Frankfurt, Gerzensee, Oestrich-Winkel, and Utrecht for helpful comments.

†Institute of Money and International Finance, Königsworther Platz 1, 30167 Hannover, Germany. Financial support from the Deutsche Forschungsgemeinschaft (DFG) is gratefully acknowledged.

${ }^{\ddagger}$ Corresponding author; Accounting and Finance Division, Stirling Management School, University of Stirling, Stirling, FK9 4LA, UK; email: patrick.herbst@stir.ac.uk.

$\S$ Justus-Liebig-University Giessen, Faculty of Economics and Business Administration, Licher Str. 74, 35394 Giessen, Germany; email: andreas.walter@wirtschaft.uni-giessen.de. 


\section{Introduction}

It is a commonly held view that investors (particularly in equity markets) have a tendency to flock together in their trading decisions, thus acting like a herd. This type of behavior is then typically associated with apparently 'irrational' market movements and supposedly threatens financial market stability. In financial economics, however, herd behavior is less easy to grasp let alone to evaluate. Theoretical models can explain herd behavior both with rational decision-making and with behavioral assumptions. A rich empirical literature therefore analyzes investor behavior and the consequences thereof on financial markets, aiming to judge whether common wisdom on the destabilizing role of investor herding holds true. However, the empirical analysis to detect, measure and evaluate herding in financial markets turns out to be challenging.

The aim of this paper is to evaluate and improve upon the standard methodology of detecting and measuring herd behavior introduced in Lakonishok, Shleifer, and Vishny (1992). ${ }^{1}$ By developing a simple structural model of investor transactions and herding, we show that the traditional herding measure is a valid test statistic for the existence of herding among investors. However, we also show that the measure may produce biased results which are thus more difficult to interpret and may also distort sample comparisons. We therefore use our simple model of trading to suggest a new, unbiased measure of herding based on observed trading behavior. We contrast the properties and advantages of our new measure to the traditional measure both theoretically and by means of Monte Carlo simulations.

Having derived our new measure of herding and its properties, we illustrate the importance of our analysis using data for German mutual fund managers. The empirical results confirm that conclusions drawn from the two measures may differ considerably, both in terms of the absolute level of herding as well as the structure of herding between sub-groups of stocks. Additionally, we show that the variables affecting the bias in the traditional measure explain the differences in our empirical findings.

Theory provides various explanations for herding which differ in causes and in their consequences for market stability (see Devenow and Welch, 1996, Bikhchandani and Sharma, 2000, or Hirshleifer and Teoh, 2003, for overviews). At the same time, several issues make

\footnotetext{
${ }^{1}$ In what follows, we use the term 'herding' to capture any type of behavior that leads to correlated trading behavior. This broader use also includes what is termed 'clustering' in Graham (1999), 'unintentional' or 'spurious' herding in Bikhchandani and Sharma (2000), or 'grouping' in Hirshleifer and Teoh (2003).
} 
empirical work on herding particularly difficult. First, there are many variants of herding: herding that is based on the observation of other market participants' actions; 'simultaneous' herding in the decision to focus on a specific set of information or in the decision to adopt a new but risky strategy; and herding based on sentiment or stock characteristics which is prone to more or less sudden changes. Second, detecting herding ideally requires the observation of actions and potentially private information - a challenge for data collection, particularly when herding is used to hide relevant information. Third, even when one does detect herding, it might be impossible to identify the causes or the consequences thereof.

One of the most influential studies in the empirical herding literature has been the analysis by Lakonishok et al. (1992). The authors introduce a statistic for herding among a subset of investors within a given time period that became one of the standard measures of herding. ${ }^{2}$ Grinblatt, Titman, and Wermers (1995) and Wermers (1999) are key papers on the US mutual fund market which apply and adjust the traditional herding measure. Over time, the measure has been applied at the stock level in many countries (see for example Choe, Kho, and Stulz, 1999 for South Korea, Kyrolainen and Perttunen, 2003, for Finland, Voronkova and Bohl, 2005, for Poland, Wylie, 2005, for the UK, Lobao and Serra, 2006, for Portgugal, Walter and Weber, 2006, for Germany), to herding in investment styles (see Choi and Sias, 2009, and Andreu, Ortiz, and Sarto, 2009) and in other securities (see Oehler and Goeth-Chi Chao, 2002, on bond markets). All these studies find significant evidence of herding among investors. In many of these markets (particularly the US and the UK markets), levels are considered relatively low (although some less developed markets seem to have higher levels of herding). Additionally, no evidence is found for destabilizing effects of herding on financial markets.

To the best of our knowledge, a model-based evaluation of the traditional herding measure has not been done before in the literature - even though the measure has been adopted in a great number of studies. This is all the more surprising as alternative approaches to herding are clearly model-based in their empirical approach (see Welch, 2000, Hwang and Salmon, 2004, Cipriani and Guarino, 2014, or Dasgupta et al., 2011b, for example). On the other hand, other aspects of the measure have been critically reviewed. In

\footnotetext{
${ }^{2}$ By focusing on within-period herding among investors, we neglect other prominent areas where herding has been studied, in particular herding among security analysts (such as the work by Graham, 1999, Welch, 2000, or Hong, Kubik, and Solomon, 2000), among investment newsletter (see Jaffe and Mahoney, 1999) or intertemporal analyses of herding (see Sias, 2004, Choi and Sias, 2009, or Dasgupta, Prat, and Verardo, 2011a,b).
} 
their overview article, Bikhchandani and Sharma (2000) mention several shortcomings of empirical measures of herding in general and of the traditional herding measure specifically. Generally, most herding measure are based on a purely statistical approach and are not linked to theoretical models of herding directly. Hence, such an approach is initially unable to differentiate between unintentional or intentional herding, or between the different potential models of herding. Therefore, more recent papers have started to incorporate herding measures into more detailed (regression) analyses in order to link observed herding to theoretical models (see, for example, Kim and Wei 2002a,b, Chan, Hwang, and Mian 2005, Massa and Patgiri 2005, Zhou and Lai 2009, or Brown, Wei, and Wermers 2014). However, such analyses require measures of herding to be sufficiently robust. Our analysis implies that the use of the traditional measure may distort empirical findings. Our suggested modifications to measuring herding thus provide a means to improve (and test) the robustness of herding analyses.

Further drawbacks of the traditional herding measure mentioned in Bikhchandani and Sharma (2000) are the lack of an inter-temporal dimension of herding as well as the measure's use of a binary measure of buys versus sells, rather than the size of the transaction. Sias (2004), Choi and Sias (2009), Andreu et al. (2009), and Gavriilidis, Kallinterakis, and Ferreira (2013) provide alternative approaches which focus on intertemporal aspects in fund managers' trading behavior. One way to account for different transaction sizes, would be to focus only on transactions of sufficient size (see Andreu et al., 2009, who also provide other means to also account for transaction size, as well as Hu, Meng, and Potter, 2008, in a slightly different context). However, we show that the traditional herding measure's bias varies with the number of transactions used in the analysis, and different filtering rules would thus distort the measure differently. This distortion does not arise in the alternative measure we suggest, such that filtering transactions would yield more robust results. ${ }^{3}$

Wylie (2005) identifies biases inherent in the traditional herding measure which arise because the (implicitly stated) underlying model may be misspecified. In particular, he argues that short-selling constraints and heterogeneity in money manager's trading propensities can induce the traditional measure to find herding where there is none. We will recon-

\footnotetext{
${ }^{3}$ There also exists a literature strand on measuring herding based on asset pricing models and observed prices following the work of Christie and Huang (1995). This strand of the literature considers herding within a market overall, rather than among a set of investors (see, for example, the international analyses of Chang, Cheng, and Khorana, 2000, Economou, Kostakis, and Philippas, 2011, or Balcilar, Demirer, and Hammoudeh, 2013). As both the focus and methodology of this strand of the literature differ from ours, we abstain from a more extensive discussion of this literature.
} 
sider these aspects in a separate discussion towards the end of the paper. While Wylie's criticism has to be taken into account, we believe that our analysis is at least as relevant: Given that basically all analyses confirm the existence of herd behavior, it is important to understand the causes and consequences of herding. However, more detailed analyses of herding require a measure of herding levels that is statistically more robust than the traditional measure. Our paper aims to fill this important gap in the empirical literature.

The remainder of the paper is structured as follows. The next section presents our approach to modeling trading behavior and to the measurement of herding. We present the traditional and our alternative herding measure, comparing their statistical properties both theoretically and in Monte Carlo simulations. In section 3, we use our new measure to analyze the German mutual fund market and contrast our findings with those that would arise under the traditional measure. In section 4, we show how our new measure applies to a more general setting. Section 5 concludes the analysis.

\section{Methodological approach}

\subsection{A simple model of herding as excess dispersion}

Our aim is to develop a model of herd behavior in investor transactions that reflects the existing empirical literature's approach. As there is no explicit model given in the literature so far, we use the information implicit in the earlier analyses. Specifically, we make use of the interpretation of estimated herding parameters for the traditional, standard measure of herding developed in Lakonishok et al. (1992). The authors, p. 30, explain their overall herding measure of 0.027 for US pension funds as follows:

$\ldots$ it implies that if $p$, the average fraction of changes that are increases, was

0.5 , then $52.7 \%$ of the money managers were changing their holdings of an average stock in one direction and $47.3 \%$ in the opposite direction.

This original interpretation has been adopted by almost all papers using the traditional herding measure. Additionally, it is always assumed that under the null hypothesis of no herding, buy (versus sell) transactions are binomially distributed with equal success probabilities for all stock in a given time period.

With this information at hand, we construct the following simple model: Consider stock $s$ during quarter $q$ (henceforth called stock-quarter $q s$ ). Let the probability that this stock 
is bought (versus sold) by a fund manager active in $q s$ be

$$
\pi^{q s}=\pi^{q}+\iota^{q s} \delta^{q s}
$$

where

$$
\iota^{q s}=\left\{\begin{array}{rl}
1 & \text { with Prob }=0.5 \\
-1 & \text { with Prob }=0.5
\end{array} .\right.
$$

In (1), $\pi^{q}$ denotes the overall probability of buys in quarter $q$ for all stocks (determined by new money flows, for example), $\delta^{q s}$ is the degree of herding in stock-quarter $q s$ and $\iota^{q s}$ is an unobservable (latent) variable indicating whether herding in the stock-quarter is on the buy $\left(\iota^{q s}=1\right)$ or sell side $\left(\iota^{q s}=-1\right)$. Furthermore, assumption (2) is a normalizing constraint such that herding is defined as the deviation from the overall buy probability in the quarter (see section 4 for a more general model). To complete the model, consider the behavior of all $n$ fund managers trading stock $s$ in $q$ : We assume that the buy probability $\pi^{q s}$ as specified in (1) applies to all $n$ fund managers. The number of buys is then the result of $n$ draws from a Bernoulli distribution with success (buy) probability of $\pi^{q s}$. (Note that the latent variable $\iota^{q s}$ is thus also identical for any fund manager active in $q s$.)

This model of trading behavior is compatible with the earlier empirical literature: (i) under the null hypothesis of zero herding, the probability of buys corresponds to the overall probability of buys during a period (with buys binomially distributed); (ii) herding is defined as a deviation from the overall buy probability during a period (as in the standard interpretation); (iii) the parameter $\iota^{q s}$ allows for herding to be either on the buy or on the sell side (again, as in the standard interpretation).

Basically, the above model defines herding as excess dispersion in either buy or sell probabilities in a single stock-quarter - in excess of what would be expected for the overall period. This can be interpreted as a trading environment where all investors receive three types of signals: (i) an overall signal for the trading period which determines the overall propensity to buy $\left(\pi^{q}\right)$; (ii) a stock-quarter specific signal $\left(\iota^{q s}\right)$ which tilts buy probabilities away from the overall mean - either increasing the buy propensity (buy herding) or decreasing it (sell herding); (iii) another stock-quarter specific signal which determines the strength of herding $\left(\delta^{q s}\right)$. 


\subsection{Herding statistics}

\subsubsection{Traditional herding statistics}

Among the various approaches to detecting and measuring herd behavior in the financial and economic literature, the measure introduced by Lakonishok et al. (1992) stands out because of its intuitive approach and interpretation. The interpretation presented in the preceding section already revealed the basic idea of this measure: Trading activity in a stock (the decision to either buy or sell) or similar binary decisions are randomly distributed with equal distribution for all categories (i.e. stocks in a quarter) when there is no herding. Any activity in a stock excessively on either the buy or sell side can then be interpreted as herd behavior. Consequently, the herding measure is constructed as a measure of excess dispersion in the observed distribution of buy and sell transactions.

Consider an individual stock-quarter $q s$ and a total of $S$ stocks traded in quarter $q$. The traditional herding statistic for $s$ in $q$ is given by

$$
H_{|1|}^{q s}=\left|\frac{b^{q s}}{n^{q s}}-\hat{\pi}^{q}\right|-\underbrace{E\left[\left|\frac{\tilde{b}^{q s}}{n^{q s}}-\hat{\pi}^{q}\right| ; \tilde{b}^{q s} \sim B\left(\hat{\pi}^{q}, n^{q s}\right)\right]}_{A F^{q s}}
$$

where $b^{q s}$ is the number of buy transactions and $n^{q s}$ the total number of transactions in stock $s$ during quarter $q \cdot{ }^{4}$ The parameter $\hat{\pi}^{q}=\frac{\sum_{s=1}^{S} b^{q s}}{\sum_{s=1}^{S} n^{q s}}$ gives the average proportion of buys to total transactions in all $S$ stocks in the quarter and thus the expected probability of a buy under the null hypothesis of no herding. The left-hand term in the $H_{|1|}^{q s}$ expression will be positive even under the null hypothesis: some degree of dispersion is to be expected given a finite number of stochastic transactions (normal dispersion). The second term, the adjustment factor $A F^{q s}$, corrects for this expected dispersion. $E\left[. ; \tilde{b}^{q s} \sim B\left(\hat{\pi}^{q}, n^{q s}\right)\right]$ thus is the expected value of the expression in square brackets when the number of buys $\tilde{b}^{q s}$ is distributed binomially with probability $\hat{\pi}^{q}$ and $n^{q s}$ independent draws. Overall, a positive herding statistic thus captures excessive dispersion on the buy or sell side at stock-quarter level. To measure herd behavior in a sample, the herding statistic for stock-quarter qs is then aggregated and averaged for all stock-quarters. Alternatively, the stock-quarter measures may be averaged for sub-groups (for example sub-periods or sub-groups of stocks).

Although the structural model above has been developed to match the past use and interpretation of the traditional herding measure, the $H_{|1|}$ measure has some drawbacks

\footnotetext{
${ }^{4}$ We use the subscript $|1|$ in order to highlight that this measure uses the first absolute moment, whereas the alternative measure presented below uses the second moment which will be denoted by subscript 2 .
} 
if transactions were generated by the model in (1) and (2). Generally, when there is no herding $\left(\delta^{q s}=0\right)$, the $H_{|1|}$ measure correctly produces an expected measure of zero. Under herding, it produces a positive measure in expectations. However, unless the number of transactions in a stock-quarter is extremely large, the expected value of the measure is biased downwards relative to the true herding parameter $\delta^{q s}$. Due to the functional form of the binomial distribution, we have to revert to numerical evaluation to show this bias. ${ }^{5}$

To illustrate the mechanisms behind the $H_{|1|}^{q s}$ statistic, figure 1 depicts the expected value of the statistic (denoted EH1) and its two components, the expected absolute dispersion when there is herding in stock $s$ (denoted EADH) and the adjustment factor (denoted AF), as functions of the number of trades in the stock. The analysis shows first that without the adjustment factor, the herding statistic would overstate the true level of herding since some degree of dispersion always results from the stochastic nature of trading behavior. However, one can also see that the adjustment factor overcorrects for the excess dispersion and leads to an understatement of herding. With the adjustment factor converging towards zero and the expected absolute dispersion with herding converging towards the true parameter for increasing number of trades in a stock, the $H_{|1|}^{q s}$ statistic approaches the true value. However, the bias becomes negligible only for very high numbers of trades in a stock. Our later simulation results show that for the number of trades found in typical empirical studies, the size of the bias is non-negligible. For example, in Wermer's analysis of US mutual funds, less than one third of the stocks are traded by 20 or more fund managers during a quarter in any of the years reported (see Wermers, 1999, Table I, Panel D).

It is less the bias inherent in the traditional herding statistic which makes its use as a measure of herding problematic, but rather the variability of this bias, most significantly in the number of trades and the true underlying herding. ${ }^{6}$ This is illustrated in figure 2 which shows that the bias decreases with higher numbers of trades in a stock and increases with

\footnotetext{
${ }^{5}$ In the appendix, we describe the technical details of this analysis. Bellando (2010) confirms our results using a slightly different approach.

${ }^{6}$ Wylie (2005), p. 391, implicitly acknowledges the bias inherent in the $H_{|1|}^{q s}$ statistic:

When $p_{t}=0.58$ and the number of managers trading is 25 , a herding figure of $9.0 \%$ corresponds approximately to 19 managers buying...

With 19 out of 25 managers buying when the expected number of buys under the null is 14 or 15 (14.5), then 19 managers buying implies a true herding parameter of 0.16 to 0.2 . Given the approximations due to rounding, this is fully in accordance with our numerical evaluations of the expected herding statistic. However, Wylie (2005) neither explicitly acknowledges this bias nor its variability, but focuses on biases which might arise when the model is misspecified.
} 
the true level of herding. At the same time, the decrease in the bias is more pronounced when true herding is higher. As a consequence, patterns of herding found among subsets of the data might be affected solely by the functional form of the bias: an increase in herding measured between two samples might be due to an increase in the number of trades, such that true herding does not necessarily increase - true herding might even decrease as the analysis in 3.2 will suggest. For example, herding among sub-groups of mutual funds are often reported to be lower than herding for the total sample (where all transactions are summed up); see Lakonishok et al. (1992), Grinblatt et al. (1995), or Wermers (1999). Similarly, Choe et al. (1999) find that herding among foreign investors decreased during the 1997 Korean crisis; however, the authors also note that foreign investors' trading also decreased during that period. Without further information on the trading activity in the pre-crisis versus crisis period, interpreting a falling $H_{|1|}$ statistic appears difficult.

On the other hand, taking into account the traditional statistic's bias would reinforce the pattern of herding if herding is found to decrease for an increasing number of trades. For example, the slight decrease in herding in Table 3 of Wermers (1999) when the minimum number of trades rises would be even more pronounced in the underlying herding parameter of our model. Similarly, Kim and Wei (2002a) show that offshore funds have lower herding measures in the Korean market while their trading intensity is lower. In this case, the potential bias also reinforces their result.

More generally, any comparison among sub-samples may be affected by the bias due to sample differences in trading activities - the most obvious being differences by the number of active funds itself (as is standard in most herding analyses) or grouping of stocks by size (larger stocks are traded more often). But also differentiating stocks by past returns may be affected if extreme performance leads to higher trading activity (due to momentum or contrarian trading strategies). Finally, more recent analyses have used the traditional herding statistic in regression analyses (see for example Kim and Wei, 2002a,b, Chan et al., 2005, Massa and Patgiri, 2005, or Brown et al., 2014) - either to determine the effect of herding on stock prices (see also Grinblatt et al., 1995) or to distinguish determinants of herding behavior (and thus theoretical explanations of herding). Using the biased herding statistic and not accounting for its dependency on trading activity (as well as the proportion of buys) may distort regression results. Given all these issues arising under the use of the $H_{|1|}$ herding statistic, we proceed by offering an alternative, modified measure and by comparing its statistical properties with the traditional measure. 


\subsubsection{Alternative measure}

While it is generally possible to calculate the bias inherent in the $H_{|1|}$ measure, we now propose a different measure of herding which provides a consistent estimate for the true herding parameter $\delta$. This statistic adopts the basic idea of the $H_{|1|}$ statistic to measure the excess dispersion of trades on either the buy or sell side. But instead of using the first absolute moment, we revert to the second (central) moment - being the traditional measure for dispersion in statistics with well-documented statistical properties. ${ }^{7}$ As before we estimate in a first step the probability of buys in a quarter by $\hat{\pi}^{q}$. Our suggested measure of herding in stock $s$ during quarter $q$ is

$$
\mathbb{H}_{2}^{q s}=\frac{\left(b^{q s}-\hat{\pi}^{q} n^{q s}\right)^{2}-n^{q s} \hat{\pi}^{q}\left(1-\hat{\pi}^{q}\right)}{n^{q s}\left(n^{q s}-1\right)},
$$

where the numerator is the empirical variance minus the expected variance of a binomial distribution with parameters $n^{q s}$ and $\hat{\pi}^{q}$. This formula is the complement to the traditional measure (now for the second moment), except for the normalization in the denominator which leads to more desirable statistical properties. ${ }^{8}$

The $\mathbb{H}_{2}$ measure may be aggregated over stock-periods: Let the set of aggregated stockperiods be labeled $\mathcal{A}$. The aggregate's measure of herding is then given by

$$
\mathbb{H}_{2}^{\mathcal{A}}=\frac{1}{\# \mathcal{A}} \sum_{q s \in \mathcal{A}} \mathbb{H}_{2}^{q s}
$$

Finally, in order to make the level of the new herding measure comparable to the traditional measure we use the square root of the aggregated herding measure

$$
H_{2}^{\mathcal{A}} \equiv \sqrt{\mathbb{H}_{2}^{\mathcal{A}}}
$$

In contrast to the $H_{|1|}$ measure, we can derive the following statistical properties of the $\mathbb{H}_{2}$ measure (and its variants) in closed form.

\footnotetext{
${ }^{7}$ The literature on absolute moments of discrete distributions is rather sparse (see for example Katti, 1960).

${ }^{8}$ The complementarity of the two measures can be seen most easily by transformation of the new measure and by omitting all superscripts. Then, the two measures are:

$$
\begin{aligned}
H_{|1|} & =\left|\frac{b}{n}-\hat{\pi}\right|-E\left[\left|\frac{\tilde{b}}{n}-\hat{\pi}\right|\right] \\
\mathbb{H}_{2} & =\left(\left(\frac{b}{n}-\hat{\pi}\right)^{2}-E\left[\left(\frac{\tilde{b}}{n}-\hat{\pi}\right)^{2}\right]\right) \frac{n}{n-1}
\end{aligned}
$$
}

where $E[$.$] denotes the expected value under the null of no herding.$ 
1. $\mathbb{H}_{2}^{q s}$ is an unbiased estimator of $\left(\delta^{q s}\right)^{2}$.

2. $\mathbb{H}_{2}^{\mathcal{A}}$ is an unbiased estimator of $\left(\delta^{\mathcal{A}}\right)^{2}$, as defined above.

3. $H_{2}^{\mathcal{A}}$ is a consistent estimator of $\delta^{\mathcal{A}}$ (that is, for $\# \mathcal{A}$ approaching infinity).

The formal derivation of these as well as further statistical properties of the alternative measure are provided in a web-appendix.

\subsection{Comparing the two measures}

So far, we have argued that the traditional herding measure $H_{|1|}$ and the new $H_{2}$ measure (the square root of $\mathbb{H}_{2}$ ) differ in terms of accurateness in estimating $\delta$. However, it is not clear which of the two measures performs statistically better in our model. By means of Monte Carlo simulations, we will thus illustrate further differences in the two measures' properties.

Our scenario considers the estimation of herding for a single stock with several quarters of trading. It is representative for other (potentially larger) aggregates like quarters or groups of stocks. To simplify matters we assume that all parameters be identical for all observations. ${ }^{9}$ The simulation covers combinations of parameters that are characteristic for the existing literature. For the number of portfolio managers trading a stock simultaneously - denoted $n$ in the tables - we chose 5, 25 and 50. The true herding parameter $\delta$ varies between 0.00 (no herding) and 0.30 (strong herding). ${ }^{10}$ The number of observations $q$ (for a single stock, this is equal to the number of stock-quarters) grows from 20 to 100 and 1000 for a very large aggregation. The parameter $\pi$ of overall buy propensity remains at 0.50 throughout the simulation study. ${ }^{11}$

In table 1 we report the means and standard deviations of the two measures for each combination of the parameters above. Treating them as estimators of the true herding parameter $\delta$ we compute the mean square error (mse) in table 2 . The mse equals the sum of the squared bias and standard deviation of the estimator, and we report both along

\footnotetext{
${ }^{9}$ We also studied a more realistic environment. As the results confirm our simple analysis, we do not report them here but make them available upon request.

${ }^{10}$ To increase readability of the tables we report $\delta$ and all estimators thereof in percentage points but omit the percentage signs.

${ }^{11}$ We performed the whole simulation study for different levels of $\pi(0.45,0.55,0.60)$ which resulted in no substantial differences to the results reported here. While the size of the bias of the $H_{|1|}$ measure varies with $\pi$, the absolute size of this variation is limited.
} 
with the mse. The means and standard deviations of estimated errors follow in table 3 . As it is desirable that the mean of the estimated error is an unbiased estimate of the true standard deviation of the estimator, we show the latter for comparison. Table 4 shows the power of the test for $\delta$ equal to zero at the $95 \%$ confidence level (including additionally the $\mathbb{H}_{2}$ measure). Figures 3 and 4 illustrate the results for mean squared errors and statistical power graphically.

Generally, we identify two basic applications for any herding measure: (i) to test whether there is herding in the sample under investigation; (ii) to measure the extent of herding (if it exists). The $H_{|1|}$ measure is very well suited for the first task. Under the null hypothesis of no herding $(\delta=0), H_{|1|}$ is unbiased with a low standard error as shown in table 1. Moreover, its estimated standard error is an unbiased estimate of its true standard deviation regardless of $\delta$ - which can be seen from table 3. Quite the opposite is true for our new measure: it is no reliable test statistic under the null hypothesis. For small samples with a low number of transactions $(n)$, a downward bias occurs that stems from the non-linearity of applying the square root to the unbiased estimator $\mathbb{H}_{2}$. Still, a viable alternative to $H_{|1|}$ is $\mathbb{H}_{2}$ as a test statistic. Table 4 clearly shows that both $H_{|1|}$ and $\mathbb{H}_{2}$ are valid tests, whereas $H_{2}$ does not conform to the chosen confidence level. Note, however, that figure 4 suggests a small advantage of $H_{|1|}$ in small samples compared to $\mathbb{H}_{2}$.

Table 2 can be used to infer which of the statistics is suitable to measuring the level of herding. For $\delta=0.15, H_{2}$ is superior to $H_{|1|}$ in terms of the mean square error (Mse) for as little as only 20 observations and five portfolio managers trading a stock. Even for $\delta$ as low as 0.05 , the new measure excels for 1000 observations of five portfolio managers trading (or 100 observations for 20 trades per stock-period, or 20 observations for 50 trades). Hence, the advantage of the new measure increases drastically with the number of observations, as illustrated in figure 3. In contrast, the Mse of $H_{|1|}$ does not improve significantly with increased numbers of observations as it is dominated by the bias (which is unaffected by the number of observations).

The results of the Monte Carlo analysis suggest a two step approach to using these herding measures in empirical applications: In a first step, existence of herd behavior should be tested using either the $H_{|1|}$ or our $\mathbb{H}_{2}$ statistic. If significant herding is confirmed, the level of herding can be estimated consistently by $\mathrm{H}_{2}$. 


\section{Application to German mutual funds}

So far, we argued that using the traditional herding statistic to measure herding may lead to false conclusions. As a way out, we also showed that our suggested new measure has certain advantages in measuring herding. This section uses data from the German mutual fund industry to illustrate how the two measures perform and differ in their results in a real data set.

\subsection{The data}

For our empirical study, we use a version of the hand-collected database introduced by Walter and Weber (2006) that has been extended to cover the period from 1998 to 2004. Our data contains portfolio holdings of mutual funds specializing in German stocks. The universe of funds consists of those funds managed by German investment companies and investment companies of German provenance domiciled in other countries. ${ }^{12}$ Passively managed funds were excluded from the analysis.

Trading activity is inferred from changes in semi-annual portfolio holdings of each fund. A stock being purchased, increased, decreased, or sold by at least three funds in a given period is defined as a stock-period. ${ }^{13}$ Since we are exclusively interested in portfolio changes that result from trades, we exclude all stock-periods induced by passive trading, for example due to stock splits. Trading data from the period preceding the closure of a fund is also excluded.

The mutual fund holdings database is supplemented with data on stock prices and market capitalization from Datastream. We sort stocks by their returns in each quarter into five return quintiles. We also use 2005 information on stock market capitalization to split the total market capitalization of stocks in the data set in quintiles. ${ }^{14}$

\footnotetext{
${ }^{12}$ See Walter and Weber (2006) for a detailed description of the data and the collection procedure as well as on the specifics of the German mutual fund market.

${ }^{13}$ Three trades is the minimum number of transactions imposed by our theoretical model in order to technically identify the herding parameter. The higher the number of trades, the higher is the precision of our measure, as illustrated in our simulations.

${ }^{14}$ Splitting total market cap into five groups of equal-sized total market cap has the advantage of retaining a sufficiently large number of observations in the small cap group of stocks. On the other hand, it leads to fewer, but highly traded stocks in the other groups.
} 


\subsection{Empirical analysis}

In what follows, we analyze the herding behavior of institutional investors in the German stock market using our new measure of herding. By contrasting our results with those that would arise under the traditional herding measure, we highlight both some new patterns not discernible under the traditional measure and the significance of the bias effect in the $H_{|1|}$ measure.

\subsubsection{Herding and trading intensity}

We start with the standard presentation of the overall herding measure with different thresholds for the minimum number of transactions in a stock. Table 5 presents the results for both herding measures as well as information on the number of observations and trading activity in each sample. As expected, the herding measured by our new statistic is considerably higher than under the traditional statistic - on average, the new measure is 2.8 times higher than the traditional measure of herding. Even more important than the pure level effect, however, is the structure of herding when the number of trades in a stock varies: whereas the traditional measure would suggest that herding monotonically increases when more fund managers trade in a stock, the comparison with our new measure shows that the monotonicity is partially induced by the bias inherent in $H_{|1|}$. As a consequence, higher levels of herding when fewer fund managers are active in a stock are only detected with our new measure of herding.

As a confirmation of our earlier formal analysis and simulation study we also find two structures in the data: First, the relative bias between the $H_{2}$ and the $H_{|1|}$ measure in table 5 decreases as expected with higher trading activity. Second, while the standard errors of our estimates are higher under the new measure, (unreported) t-values suggest that the precision of our estimates has increased. Given the high number of observations in the sub-groups, this accords well with the statistical properties derived in our Monte Carlo simulation study. ${ }^{15}$ Additionally, while the absolute values of herding and differences between the class estimates increase under our new measure (see the standard deviation of the estimates), it is worth noting that the relative variation around the mean herding level decreases. Hence, while the new measure suggests significantly higher levels of herding and

\footnotetext{
${ }^{15}$ Consider for example the simulation with parameters $n=5, q=100, \pi=0.5$ and $\delta=15 \%$ - a representation that is still unfavorable towards $H_{2}$ compared to the available data. Even then, our new measure already achieves higher relative precision than the $H_{|1|}$ measure (see table 1 ).
} 
a different structure among the sub-sets, we also find that the relative differences between classes of stocks is less pronounced than under the traditional measure.

Since the results in table 5 are influenced by aggregation, it is instructive to consider non-overlapping sub-groups of the total sample differing in trading activity, as is done in table 6 . The results for the $H_{2}$ measure reinforce the $\mathrm{u}$-shaped structure of herding with respect to trading activity of table 5 , whereas the results for the traditional measure are less clear-cut.

\subsubsection{Herding and stock size}

Another important analysis of herding among money managers centers on whether herd behavior differs among stocks of different sizes. For example, higher herding among small stocks might be attributed to less information available and hence to managers being more inclined to follow others or the consensus. Among large stocks, on the other hand, one might observe informational herding as these companies are closely followed by a large number of analysts and money managers, all relying on the same (publicly available) information. Generally, preferences towards/against one or the other class of stocks as reported in Falkenstein (1996) may increase the correlation in trading decisions.

Table 7 reports herding parameters for sub-groups of stocks sorted by market capitalization such that total market capitalization is divided into quintiles. According to the traditional herding measure, herding among smaller stocks appears to be below average, while large stocks show the highest levels of herding. However, the number of fund managers trading a stock is positively related to its market capitalization - as already stressed by Wermers (1999). Consequently, we would expect higher levels of herding measured by $H_{|1|}$ for larger stocks simply due to the lower bias. This effect is confirmed in our data: first, while being generally at higher levels, herding among small stocks is at a higher level than among the largest stocks which show the second-highest herding levels. Second, looking at the relative bias reported in table 7 , the relationship between the different results and the level of trading activity is apparent: higher trading activity in larger stocks reduces the bias in the herding measured with $H_{|1|}$ - as in the previous tables 5 and 6 . As a consequence, our new measure leads to a structure of herding very similar to the comparison along activity levels: herding is also u-shaped when stocks are grouped by their size. 


\subsubsection{Herding in sub-periods}

Table 8 analyzes the changes in fund manager herding over time. Unlike in the tables before, there is no clear-cut trend in the average number of trades per stock between subperiods - the range of 9.4 to 11 trades per stock is fairly narrow. Similarly, the relative deviation between herding measured by our new and the traditional measure - albeit significant in terms of its level - remains fairly constant. As a consequence, the pattern of changes in herding is similar for both measures: the highest levels of herding can be observed at the height and during the bursting of the so-called 'internet bubble' (2000 and 2001) with a sharp drop in herding levels in the post-bubble period (2002 onwards).

Given that trading activity over the years did not vary a lot, it is interesting to note that the relationship between the two measures is still as we expect it to be from our theoretical analysis: looking at the years 2001 to 2003 (all with approximately eleven transactions per stock), the relative difference between the two measures decreases with the estimated level of true herding as measured by $\mathrm{H}_{2}$. Finally, note that while our data set shows stability of trading activity over time, this need not be the case for other data sets or longer periods. During the period of 20 years studied by Wermers (1999), for example, there is a considerable increase in the number of transactions per stock. Similarly, Choe et al. (1999) note that liquidity (and consequently trading activity) decreased markedly during the 1997 Korean crisis. Comparisons of the crisis period with other periods might then be distorted by changes in the expected bias in the traditional measure.

\subsection{How important are differences in the two measures' findings?}

In a last step, we consider again the results of our preceding analyses for the German mutual fund market. Specifically, we look at common or diverging structures between the traditional and our new herding measure for the five analyses in tables 5 to 8 . Panel A of table 9 presents the results from regressing the absolute difference between $H_{2}$ and $H_{|1|}$ (the absolute bias) on an intercept, trading activity (the mean number of trades per stock), the level of $H_{2}$ (as the supposedly 'true' level of herding) and the number of observations in the sub-sample. ${ }^{16}$ The results from these regression are highly similar and can all be explained by our earlier formal and simulation analyses of the two measures. First, the parameter for the number of trades per stock is significant and negative - an increase in

\footnotetext{
${ }^{16}$ In table 9, we also report the R-Square of each regression. Of course, these numbers are highly inflated due to the very low numbers of observations.
} 
trading activity increases the $H_{|1|}$ measure towards the true level of herding measured by $H_{2}$. Second, an increase in $H_{2}$ (as the true level of herding) increases the absolute bias of the traditional measure. Finally, the number of observations does not have any significant influence on the bias - most probably due to a sufficiently high number of stock-periods in each of our sub-samples.

Panel B of table 9 reconsiders again whether the two measures diverge in their ranking of sub-samples given the herding measured. Here, the rank correlation coefficients paint a more diverse picture: For the first three analyses (herding depending on trading activity and stock size), the two measures differ greatly in their results. This repeats our earlier comments that the traditional herding measure is greatly influenced by the level of trading activity in these analyses. As a consequence, conclusions drawn from either of the two measures will differ considerably. It is only for the last analysis (years) that the rank correlation coefficient is both significant and fairly close to one. Hence, only in this last analysis does the use of either of the two measures not materially affect the results.

\section{Discussion: Herding as excess dispersion}

In what follows, we show that our suggested new measure can be applied to a more generalized model of trading behavior under herding. We then discuss how the criticism of Wylie (2005) may be addressed within our theoretical structure.

\subsection{A generalized model of trading behavior}

Consider again our simple model of trading behavior as specified in section 2.1. Due to the random variable $\iota^{q s}$, the buy probability $\pi^{q s}$ is itself a random variable, with moments

$$
E\left[\pi^{q s}\right]=\pi^{q} \quad \text { and } \quad \operatorname{Var}\left[\pi^{q s}\right]=\delta^{2}
$$

The essential feature of this model is that buy probabilities vary over stock-quarters but are identical within stock-quarters. This feature is shared by the more general Lexian sampling scheme (see Johnson, Kotz, and Kemp, 1992). Lexian sampling describes a specific application of the binomial distribution where the success (buy) probabilities vary across throws (in our case stock-quarters) but remain constant within throws. ${ }^{17}$ The heterogeneity of the

\footnotetext{
${ }^{17}$ The opposite would be Poissonian binomial sampling which is discussed in the following subsection. See Johnson et al. (1992), chapter 3, for more details on both samplings of the binomial distribution.
} 
success probability is represented by the between-throw variance $\sigma_{b}^{2}$. Then, the following assumptions for the probability of a buy in a stock-quarter $q s$ define a more generalized model of herding:

$$
\pi^{q s} \in[0,1] \quad, \quad E\left[\pi^{q s}\right]=\bar{\pi} \text { and } \operatorname{Var}\left[\pi^{q s}\right]=\sigma_{b}^{2}
$$

This contains the model of section 2.1 as a special case. As a consequence, the assumptions in our simple model of trading are more restrictive than necessary. The variance for the Lexian sampling of the binomial distribution is increased by $n(n-1) \sigma_{b}^{2}$ compared to the case of homogeneity with a parameter of $\bar{\pi}$. Measuring the excess dispersion is the idea underlying our new measure. Given the properties of the Lexian sampling, $\mathbb{H}_{2}$ provides an unbiased estimate of the between-throw variance $\sigma_{b}^{2}$. Hence, our new measure remains a valid estimator in this more general setting. ${ }^{18}$

\subsection{Heterogeneity and short-selling constraints}

Wylie (2005) identifies two critical assumptions implicit in the traditional $H_{|1|}$ measure: no short-selling constraints and identical buy probabilities for fund managers in any stockquarter. By simulation, he shows that introducing short-selling constraints and heterogeneity in buy probabilities within stock-quarters biases the $H_{|1|}$ measure under the null hypothesis of no herding.

In our theoretical structure, heterogeneity of buy probabilities within a stock-quarter could be captured by the Poissonian binomial sampling. Under Poissonian sampling, within-throw variance of the success probabilities actually decreases the overall variance of the number of successes. As a consequence, any measure of herding as excess dispersion which does not take heterogeneity in buy probabilities into account underestimates the full extent of the between-throw variance. For the $H_{|1|}$ measure, Wylie (2005) confirms this downward bias in his simulation study (see table 4 in his analysis), and a similar effect might be expected for our new measure.

Starting from our model of trading, the effect of short-selling constraints can be decomposed into two opposing mechanisms: First, when differences in initial stock holdings differ

\footnotetext{
${ }^{18}$ Bellando (2010) argues that our measure provides a biased measure of herding in her slightly more general model. However, this difference is due to a different definition of herding. Her numerical results actually confirm that our measure exactly captures the variance of the buy probabilities implied by her model.
} 
mostly between stocks (some stocks are generally held more than others), then buy probabilities are heterogeneous across different stock-quarters. This would be captured by the aforementioned Lexian sampling and thus potentially inflates the herding levels measured. Second, however, fund managers may differ in their holding of a stock at the beginning of a quarter. For example, the simulation by Wylie (2005) assigns different probabilities for buys and sells depending on the initial holding of a fund manager, thus introducing heterogeneity of buy probabilities within a stock-quarter. As discussed above, this Poissonian sampling would distort measured herding levels downwards. Overall, we thus identify competing biases for short-selling constraints. The fact that Wylie (2005) finds an overall inflating effect of short-selling constraints on the $H_{|1|}$ measure suggests that the former effect (heterogeneity in initial holdings across stock-quarters) dominates in the UK data set.

\section{Conclusion}

Understanding the causes of herd behavior in financial markets and its effects on asset prices and thus market stability is of high relevance to both academics and decision-makers in the area of market regulation. Direct observations of investors' trading behavior is a promising basis for empirical analyses on herding. The past literature has already suggested that herding among investors can be observed. The observed herd behavior so far is either considered negligible low or turns out not to be destabilizing.

This paper argues that when measuring the degree of herding (either in terms of absolute levels, in mean comparisons among samples or in regression analyses), relying on the traditional herding statistic introduced in Lakonishok et al. (1992) may produce results that are difficult to interpret. While a general distortion in the traditional measure might not matter a lot, we show that the bias interacts with other parameters in a data set and might thus mislead researchers in their conclusions. For this reason, we use a model of trading behavior and herding to derive alternative means to estimate herding that possess superior statistical properties. Mohamed Sr., Bellando, Ringuede, and Vaubourg (2011) and Merli and Roger (2012) apply our new measure to analyze herding among French investors, while Frot and Santiso (2011) use our approach to measure herding in the context of foreign aid allocation.

Our results are all based on a simple theoretical structure of trading behavior which is influenced by herd behavior. While we believe that this model already captures previous 
studies' approach to herding, it is also an obvious starting point for further development. Fruitful areas for further analysis would be proper specifications of buy versus sell herding measures, including a more thorough incorporation of the issues raised in Wylie (2005), for example. Another direction of future research is to extend the model by incorporating those variables that typically explain the amount of herding. Postulating a model of trading behavior and herding appears to be a necessary prerequisite to properly analyze herd behavior. In this sense, we consider our analysis as a step in a direction that will further improve our understanding of investor behavior in financial markets. 


\section{References}

Andreu, L., C. Ortiz, and J. L. Sarto (2009). Herding behaviour in strategic asset allocations: new approaches on quantitative and intertemporal imitation. Applied Financial Economics 19(20), 1649 - 1659.

Balcilar, M., R. Demirer, and S. Hammoudeh (2013). Investor herds and regime-switching: Evidence from Gulf Arab stock markets. Journal of International Financial Markets, Institutions and Money 23, 295 - 321.

Bellando, R. (2010). Measuring Herding Intensity: A Hard Task. SSRN Working Paper.

Bikhchandani, S. and S. Sharma (2000). Herd Behavior in Financial Markets. IMF Staff Papers $47(3), 279-310$.

Brown, N. C., K. D. Wei, and R. Wermers (2014). Analyst recommendations, mutual fund herding, and overreaction in stock prices. Management Science 60(1), $1-20$.

Chan, K., C.-Y. Hwang, and G. M. Mian (2005). Mutual Fund Herding and Dispersion of Analysts' Earnings Forecasts. SSRN Working Paper.

Chang, E. C., J. W. Cheng, and A. Khorana (2000). An Examination of Herd Behavior in Equity Markets: An International Perspective. Journal of Banking and Finance 24(10), $1651-79$.

Choe, H., B.-C. Kho, and R. M. Stulz (1999). Do Foreign Investors Destabilize Stock Markets? The Korean Experience in 1997. Journal of Financial Economics 54(2), $227-64$.

Choi, N. and R. W. Sias (2009). Institutional industry herding. Journal of Financial Economics 94(3), $469-491$.

Christie, W. G. and R. D. Huang (1995). Following the pied piper: Do individual returns herd around the market? Financial Analysts Journal 51(4), 31-37.

Cipriani, M. and A. Guarino (2014). Estimating a structural model of herd behavior in financial markets. American Economic Review 104(1), 224-51.

Dasgupta, A., A. Prat, and M. Verardo (2011a). Institutional trade persistence and longterm equity returns. Journal of Finance 66(2), 635 - 653. 
Dasgupta, A., A. Prat, and M. Verardo (2011b). The price impact of institutional herding. Review of Financial Studies $24(3), 892-925$.

Devenow, A. and I. Welch (1996). Rational herding in financial economics. European Economic Review 40(3-5), 603-15.

Economou, F., A. Kostakis, and N. Philippas (2011). Cross-country effects in herding behaviour: Evidence from four south European markets. Journal of International Financial Markets, Institutions and Money 21(3), 443 - 460.

Falkenstein, E. G. (1996). Preferences for stock characteristics as revealed by mutual fund portfolio holdings. Journal of Finance 51(1), 111-135.

Frot, E. and J. Santiso (2011). Herding in Aid Allocation. KYKLOS 64 (1), 54-74.

Gavriilidis, K., V. Kallinterakis, and M. P. L. Ferreira (2013). Institutional industry herding: Intentional or spurious? Journal of International Financial Markets, Institutions and Money 26, $192-214$.

Graham, J. R. (1999). Herding among Investment Newsletters: Theory and Evidence. Journal of Finance 54(1), 237-68.

Grinblatt, M., S. Titman, and R. Wermers (1995). Momentum Investment Strategies, Portfolio Performance, and Herding: A Study of Mutual Fund Behavior. American Economic Review 85(5), 1088-1105.

Hirshleifer, D. and S. H. Teoh (2003). Herd Behaviour and Cascading in Capital Markets: A Review and Synthesis. European Financial Management 9(1), 25-66.

Hong, H., J. D. Kubik, and A. Solomon (2000). Security Analysts' Career Concerns and Herding of Earnings Forecasts. RAND Journal of Economics 31(1), 121-44.

Hu, G., J. G. Meng, and M. E. Potter (2008). Opinion divergence among professional investment managers. Journal of Business Finance \& Accounting 35(5-6), 679-703.

Hwang, S. and M. Salmon (2004). Market Stress and Herding. Journal of Empirical Finance 11(4), 585-616.

Jaffe, J. F. and J. M. Mahoney (1999). The performance of investment newsletters. Journal of Financial Economics 53(2), 289-307. 
Johnson, N. L., S. Kotz, and A. W. Kemp (1992). Univariate discrete distributions (2. ed. ed.). New York: Wiley.

Katti, S. K. (1960). Moments of the Absolute Difference and Absolute Deviation of Discrete Distributions. The Annals of Mathematical Statistics 31(1), 78-85.

Kim, W. and S.-J. Wei (2002a). Foreign Portfolio Investors before and during a Crisis. Journal of International Economics 56(1), 77-96.

Kim, W. and S.-J. Wei (2002b). Offshore Investment Funds: Monsters in Emerging Markets? Journal of Development Economics 68(1), 205-24.

Kyrolainen, P. and J. Perttunen (2003). Investors' Activity and Trading Behavior. SSRN Working Paper.

Lakonishok, J., A. Shleifer, and R. W. Vishny (1992). The Impact of Institutional Trading on Stock Prices. Journal of Financial Economics 32(1), 23-43.

Lobao, J. and A. P. Serra (2006). Herding behaviour: Evidence from portuguese mutual funds. In G. N. Gregoriou (Ed.), Diversification and Portfolio Management of Mutual Funds, pp. 167-197. Palgrave Macmillan.

Massa, M. and R. Patgiri (2005). Compensation and Managerial Herding: Evidence from the Mutual Fund Industry. Working Paper, INSEAD.

Merli, M. and T. Roger (2012). What Drives the Herding Behavior of Individual Investors? SSRN Working Paper.

Mohamed Sr., A., R. Bellando, S. Ringuede, and A.-G. Vaubourg (2011). Institutional Herding in Stock Markets: Empirical Evidence from French Mutual Funds. SSRN Working Paper.

Oehler, A. and G. Goeth-Chi Chao (2002). Institutional Herding in Bond Markets. SSRN Working Paper.

Sias, R. W. (2004). Institutional Herding. Review of Financial Studies 17(1), 165-206.

Voronkova, S. and M. T. Bohl (2005). Institutional traders' behavior in an emerging stock market: Empirical evidence on polish pension fund investors. Journal of Business Finance 8 Accounting 32(7/8), 1537 - 1560. 
Walter, A. and F. M. Weber (2006). Herding in the German mutual fund industry. European Financial Management 12(3), 375-406.

Welch, I. (2000). Herding among Security Analysts. Journal of Financial Economics 58(3), 369-96.

Wermers, R. (1999). Mutual Fund Herding and the Impact on Stock Prices. Journal of Finance 54(2), 581-622.

Wylie, S. (2005). Fund Manager Herding: A Test of the Accuracy of Empirical Results Using U.K. Data. Journal of Business 78(1), 381-403.

Zhou, R. T. and R. N. Lai (2009). Herding and information based trading. Journal of Empirical Finance 16(3), 388 - 393. 


\section{Appendix}

\section{Numerical evaluation of the $H_{|1|}$ statistic}

This appendix illustrates how the expected value of the $H_{|1|}$ measure is derived when trading in a stock follows the (binomial) model in (1) ${ }^{19}$ Consider a specific stock-period $q s$ with herding $\delta$ (assuming $\iota=1$ ) and overall buy probability $\bar{\pi}$ (ignore superscripts $q s$ in what follows). Let $n$ be the number of transactions in the stock. Then, the probability that there are $b \in[0 ; n]$ buy transactions is

$$
\operatorname{Prob}(b ;(n, \pi))=\left(\begin{array}{l}
n \\
b
\end{array}\right) \pi^{b}(1-\pi)^{n-b}
$$

where $\pi=\bar{\pi}+\delta$. Then, the expected value of the absolute deviation of the proportion of buys from the average proportion $(\bar{\pi})$ is

$$
E\left[\left|\frac{\tilde{b}}{n}-\bar{\pi}\right| ;(\pi, n)\right]=\sum_{b=0}^{n} \operatorname{Prob}(b ;(n, \pi))\left|\frac{b}{n}-\bar{\pi}\right|
$$

which is the expected value of the first term in the $H_{|1|}$ measure (see (3)). The adjustment factor is then the same expression with $\pi=\bar{\pi}$. Hence, the expected $H_{|1|}$ measure is

$$
\begin{aligned}
E\left[H_{|1|}\right]= & 0.5 \cdot E\left[\left|\frac{\tilde{b}}{n}-\bar{\pi}\right| ;(\bar{\pi}+\delta, n)\right]+0.5 \cdot E\left[\left|\frac{\tilde{b}}{n}-\bar{\pi}\right| ;(\bar{\pi}-\delta, n)\right] \\
& -E\left[\left|\frac{\tilde{b}}{n}-\bar{\pi}\right| ;(\bar{\pi}, n)\right]
\end{aligned}
$$

The above expressions are then used to calculate the expected $H_{|1|}$ measures, its components and biases plotted in figures 1 to 2 . The specific parameters used were:

- For figure 1: $n=2, \ldots, 40, \bar{\pi}=0.5$ and $\delta=0.1$

- For figure $2: n=2, \ldots, 40, \bar{\pi}=0.5$ and $\delta \in\{0.05,0.1,0.15,0.2\}$

\footnotetext{
${ }^{19}$ In what follows we will use the notation $E[. ;(\pi, n)]$ to denote the expected value when the number of buys is binomially distributed with probability $\pi$ and $n$ draws.
} 
Table 1: MC study: mean and standard deviation of herding measures

\begin{tabular}{|c|c|c|c|c|c|c|c|c|c|c|}
\hline \multirow[b]{3}{*}{$\mathrm{n}$} & \multirow[b]{3}{*}{$\mathrm{q}$} & & \multicolumn{8}{|c|}{ True herding $\delta$ (in percent) } \\
\hline & & & \multicolumn{2}{|c|}{0.0} & \multicolumn{2}{|c|}{5.0} & \multicolumn{2}{|c|}{15.0} & \multicolumn{2}{|c|}{30.0} \\
\hline & & & $H_{|1|}$ & $H_{2}$ & $H_{|1|}$ & $\mathrm{H}_{2}$ & $H_{|1|}$ & $H_{2}$ & $H_{|1|}$ & $H_{2}$ \\
\hline \multirow[t]{6}{*}{5} & 20 & Mean & -0.0 & -0.4 & 0.3 & 1.1 & 3.3 & 12.1 & 12.6 & 29.6 \\
\hline & & Stddev & 2.7 & 11.8 & 2.7 & 11.8 & 3.1 & 10.2 & 3.3 & 4.5 \\
\hline & 100 & Mean & -0.0 & -0.1 & 0.3 & 2.1 & 3.3 & 14.5 & 12.6 & 29.9 \\
\hline & & Stddev & 1.2 & 7.9 & 1.2 & 7.8 & 1.3 & 3.7 & 1.5 & 2.0 \\
\hline & 1000 & Mean & 0.0 & -0.0 & 0.3 & 3.9 & 3.3 & 14.9 & 12.6 & 29.9 \\
\hline & & Stddev & 0.3 & 4.4 & 0.3 & 3.7 & 0.4 & 1.0 & 0.4 & 0.6 \\
\hline \multirow[t]{6}{*}{20} & 20 & Mean & 0.0 & -0.2 & 0.8 & 2.9 & 7.0 & 14.7 & 21.1 & 29.9 \\
\hline & & Stddev & 1.5 & 5.6 & 1.6 & 5.7 & 2.0 & 2.7 & 1.9 & 2.0 \\
\hline & 100 & Mean & -0.0 & -0.0 & 0.8 & 4.2 & 7.0 & 14.9 & 21.1 & 29.9 \\
\hline & & Stddev & 0.6 & 3.7 & 0.7 & 3.0 & 0.9 & 1.2 & 0.8 & 0.9 \\
\hline & 1000 & Mean & 0.0 & 0.0 & 0.8 & 4.9 & 7.0 & 15.0 & 21.1 & 29.9 \\
\hline & & Stddev & 0.2 & 2.1 & 0.2 & 0.7 & 0.2 & 0.3 & 0.2 & 0.2 \\
\hline \multirow[t]{6}{*}{50} & 20 & Mean & 0.0 & -0.1 & 1.3 & 4.1 & 9.4 & 14.9 & 24.4 & 29.9 \\
\hline & & Stddev & 0.9 & 3.5 & 1.1 & 3.0 & 1.4 & 1.6 & 1.2 & 1.2 \\
\hline & 100 & Mean & -0.0 & -0.0 & 1.3 & 4.8 & 9.4 & 14.9 & 24.3 & 29.9 \\
\hline & & Stddev & 0.4 & 2.3 & 0.5 & 1.0 & 0.6 & 0.7 & 0.5 & 0.5 \\
\hline & 1000 & Mean & -0.0 & -0.0 & 1.3 & 4.9 & 9.4 & 15.0 & 24.3 & 29.9 \\
\hline & & Stddev & 0.1 & 1.3 & 0.1 & 0.3 & 0.2 & 0.2 & 0.1 & 0.1 \\
\hline
\end{tabular}

Notes: This table reports the mean and the standard deviation (Stddev) of the two herding measures $H_{|1|}$ and $H_{2}$. Monte Carlo simulation study includes 10,000 repetitions for each parameter combination. Parameter $\pi$ is set to 0.5 in all simulations. 
Table 2: MC study: bias, standard deviation, and mean square error

\begin{tabular}{|c|c|c|c|c|c|c|c|c|c|c|}
\hline \multirow[b]{3}{*}{$\mathrm{n}$} & \multirow[b]{3}{*}{$\mathrm{q}$} & & \multicolumn{8}{|c|}{ True herding $\delta$ (in percent) } \\
\hline & & & \multicolumn{2}{|c|}{0.0} & \multicolumn{2}{|c|}{5.0} & \multicolumn{2}{|c|}{15.0} & \multicolumn{2}{|c|}{30.0} \\
\hline & & & $H_{|1|}$ & $\mathrm{H}_{2}$ & $H_{|1|}$ & $\mathrm{H}_{2}$ & $H_{|1|}$ & $\mathrm{H}_{2}$ & $H_{|1|}$ & $\mathrm{H}_{2}$ \\
\hline \multirow[t]{9}{*}{5} & \multirow[t]{3}{*}{20} & Bias & -0.0 & -0.4 & -4.6 & -3.8 & -11.6 & -2.8 & -17.3 & -0.3 \\
\hline & & Stddev & 2.7 & 11.8 & 2.7 & 11.8 & 3.1 & 10.2 & 3.3 & 4.5 \\
\hline & & Mse & 7.3 & 140.2 & 28.8 & 155.6 & 145.4 & 112.9 & 311.3 & 20.8 \\
\hline & \multirow[t]{3}{*}{100} & Bias & -0.0 & -0.1 & -4.6 & -2.8 & -11.6 & -0.4 & -17.3 & -0.0 \\
\hline & & Stddev & 1.2 & 7.9 & 1.2 & 7.8 & 1.3 & 3.7 & 1.5 & 2.0 \\
\hline & & Mse & 1.4 & 63.1 & 23.0 & 69.9 & 138.1 & 13.9 & 302.3 & 4.0 \\
\hline & \multirow[t]{3}{*}{1000} & Bias & 0.0 & -0.0 & -4.6 & -1.0 & -11.6 & -0.0 & -17.3 & -0.0 \\
\hline & & Stddev & 0.3 & 4.4 & 0.3 & 3.7 & 0.4 & 1.0 & 0.4 & 0.6 \\
\hline & & Mse & 0.1 & 19.9 & 21.5 & 15.2 & 136.7 & 1.0 & 300.0 & 0.3 \\
\hline \multirow[t]{9}{*}{20} & \multirow[t]{3}{*}{20} & Bias & 0.0 & -0.2 & -4.1 & -2.0 & -7.9 & -0.2 & -8.8 & -0.0 \\
\hline & & Stddev & 1.5 & 5.6 & 1.6 & 5.7 & 2.0 & 2.7 & 1.9 & 2.0 \\
\hline & & Mse & 2.3 & 32.2 & 19.7 & 37.3 & 68.0 & 7.6 & 81.3 & 4.1 \\
\hline & \multirow[t]{3}{*}{100} & Bias & -0.0 & -0.0 & -4.1 & -0.7 & -7.9 & -0.0 & -8.8 & -0.0 \\
\hline & & Stddev & 0.6 & 3.7 & 0.7 & 3.0 & 0.9 & 1.2 & 0.8 & 0.9 \\
\hline & & Mse & 0.4 & 14.2 & 17.5 & 9.8 & 64.8 & 1.4 & 78.2 & 0.8 \\
\hline & \multirow[t]{3}{*}{1000} & Bias & 0.0 & 0.0 & -4.1 & -0.0 & -7.9 & 0.0 & -8.8 & -0.0 \\
\hline & & Stddev & 0.2 & 2.1 & 0.2 & 0.7 & 0.2 & 0.3 & 0.2 & 0.2 \\
\hline & & Mse & 0.0 & 4.5 & 17.1 & 0.4 & 64.0 & 0.1 & 77.6 & 0.0 \\
\hline \multirow[t]{9}{*}{50} & \multirow[t]{3}{*}{20} & Bias & 0.0 & -0.1 & -3.6 & -0.8 & -5.5 & -0.0 & -5.5 & -0.0 \\
\hline & & Stddev & 0.9 & 3.5 & 1.1 & 3.0 & 1.4 & 1.6 & 1.2 & 1.2 \\
\hline & & Mse & 0.9 & 12.7 & 14.6 & 10.1 & 32.8 & 2.6 & 32.9 & 1.6 \\
\hline & \multirow[t]{3}{*}{100} & Bias & -0.0 & -0.0 & -3.6 & -0.1 & -5.5 & -0.0 & -5.6 & -0.0 \\
\hline & & Stddev & 0.4 & 2.3 & 0.5 & 1.0 & 0.6 & 0.7 & 0.5 & 0.5 \\
\hline & & Mse & 0.1 & 5.7 & 13.6 & 1.2 & 31.0 & 0.5 & 31.8 & 0.3 \\
\hline & \multirow[t]{3}{*}{1000} & Bias & -0.0 & -0.0 & -3.6 & -0.0 & -5.5 & 0.0 & -5.6 & -0.0 \\
\hline & & Stddev & 0.1 & 1.3 & 0.1 & 0.3 & 0.2 & 0.2 & 0.1 & 0.1 \\
\hline & & Mse & 0.0 & 1.7 & 13.3 & 0.0 & 30.7 & 0.0 & 31.5 & 0.0 \\
\hline
\end{tabular}

Notes: This table reports the bias, standard deviation (Stddev) and the mean square error (Mse) of the two herding measures $H_{|1|}$ and $H_{2}$. Monte Carlo simulation study includes 10,000 repetitions for each parameter combination. Parameter $\pi$ is set to 0.5 in all simulations. The Mse is multiplied by 10,000 equivalent to $\delta$ displayed in percent. 
Table 3: MC study: standard error analysis

\begin{tabular}{|c|c|c|c|c|c|c|c|c|c|c|}
\hline \multirow[b]{3}{*}{$\mathrm{n}$} & \multirow[b]{3}{*}{$\mathrm{q}$} & & \multicolumn{8}{|c|}{ True herding $\delta$ (in percent) } \\
\hline & & & \multicolumn{2}{|c|}{0.0} & \multicolumn{2}{|c|}{5.0} & \multicolumn{2}{|c|}{15.0} & \multicolumn{2}{|c|}{30.0} \\
\hline & & & $H_{|1|}$ & $H_{2}$ & $H_{|1|}$ & $H_{2}$ & $H_{|1|}$ & $H_{2}$ & $H_{|1|}$ & $H_{2}$ \\
\hline \multirow[t]{9}{*}{5} & \multirow[t]{3}{*}{20} & Mean Stderr & 2.6 & 7.2 & 2.7 & 7.3 & 3.0 & 7.2 & 3.3 & 4.5 \\
\hline & & Stddev Stderr & 0.4 & 3.7 & 0.4 & 3.7 & 0.4 & 2.8 & 0.3 & 0.6 \\
\hline & & Stddev & 2.7 & 11.8 & 2.7 & 11.8 & 3.1 & 10.2 & 3.3 & 4.5 \\
\hline & \multirow[t]{3}{*}{100} & Mean Stderr & 1.2 & 5.8 & 1.2 & 5.8 & 1.3 & 3.4 & 1.5 & 1.9 \\
\hline & & Stddev Stderr & 0.0 & 2.9 & 0.0 & 2.9 & 0.0 & 1.0 & 0.0 & 0.1 \\
\hline & & Stddev & 1.2 & 7.9 & 1.2 & 7.8 & 1.3 & 3.7 & 1.5 & 2.0 \\
\hline & \multirow[t]{3}{*}{1000} & Mean Stderr & 0.3 & 3.7 & 0.3 & 3.1 & 0.4 & 1.0 & 0.4 & 0.6 \\
\hline & & Stddev Stderr & 0.0 & 2.3 & 0.0 & 2.0 & 0.0 & 0.0 & 0.0 & 0.0 \\
\hline & & Stddev & 0.3 & 4.4 & 0.3 & 3.7 & 0.4 & 1.0 & 0.4 & 0.6 \\
\hline \multirow[t]{9}{*}{20} & \multirow[t]{3}{*}{20} & Mean Stderr & 1.5 & 4.4 & 1.6 & 4.5 & 2.0 & 2.6 & 1.9 & 2.0 \\
\hline & & Stddev Stderr & 0.2 & 3.1 & 0.2 & 2.9 & 0.3 & 0.4 & 0.3 & 0.2 \\
\hline & & Stddev & 1.5 & 5.6 & 1.6 & 5.7 & 2.0 & 2.7 & 1.9 & 2.0 \\
\hline & \multirow[t]{3}{*}{100} & Mean Stderr & 0.6 & 3.3 & 0.7 & 2.6 & 0.9 & 1.1 & 0.8 & 0.9 \\
\hline & & Stddev Stderr & 0.0 & 2.5 & 0.0 & 1.8 & 0.0 & 0.0 & 0.0 & 0.0 \\
\hline & & Stddev & 0.6 & 3.7 & 0.7 & 3.0 & 0.9 & 1.2 & 0.8 & 0.9 \\
\hline & \multirow[t]{3}{*}{1000} & Mean Stderr & 0.2 & 1.9 & 0.2 & 0.6 & 0.2 & 0.3 & 0.2 & 0.2 \\
\hline & & Stddev Stderr & 0.0 & 1.7 & 0.0 & 0.0 & 0.0 & 0.0 & 0.0 & 0.0 \\
\hline & & Stddev & 0.2 & 2.1 & 0.2 & 0.7 & 0.2 & 0.3 & 0.2 & 0.2 \\
\hline \multirow[t]{9}{*}{50} & \multirow[t]{3}{*}{20} & Mean Stderr & 0.9 & 2.9 & 1.1 & 2.5 & 1.4 & 1.5 & 1.2 & 1.2 \\
\hline & & Stddev Stderr & 0.1 & 2.4 & 0.1 & 1.6 & 0.2 & 0.2 & 0.2 & 0.1 \\
\hline & & Stddev & 0.9 & 3.5 & 1.1 & 3.0 & 1.4 & 1.6 & 1.2 & 1.2 \\
\hline & \multirow[t]{3}{*}{100} & Mean Stderr & 0.4 & 2.1 & 0.5 & 1.0 & 0.6 & 0.7 & 0.5 & 0.5 \\
\hline & & Stddev Stderr & 0.0 & 1.8 & 0.0 & 0.2 & 0.0 & 0.0 & 0.0 & 0.0 \\
\hline & & Stddev & 0.4 & 2.3 & 0.5 & 1.0 & 0.6 & 0.7 & 0.5 & 0.5 \\
\hline & \multirow[t]{3}{*}{1000} & Mean Stderr & 0.1 & 1.2 & 0.1 & 0.3 & 0.2 & 0.2 & 0.1 & 0.1 \\
\hline & & Stddev Stderr & 0.0 & 1.2 & 0.0 & 0.0 & 0.0 & 0.0 & 0.0 & 0.0 \\
\hline & & Stddev & 0.1 & 1.3 & 0.1 & 0.3 & 0.2 & 0.2 & 0.1 & 0.1 \\
\hline
\end{tabular}

Notes: This table reports the mean and the standard deviation of the estimated standard error (Mean Stderr and Stddev Stderr, respectively) in the simulation. For comparison it reports again the standard deviation (Stddev) for each of the two herding measures $H_{|1|}$ and $H_{2}$. Monte Carlo simulation study includes 10,000 repetitions for each parameter combination. Parameter $\pi$ is set to 0.5 in all simulations. 
Table 4: MC study: statistical power of herding test

\begin{tabular}{|c|c|c|c|c|c|c|c|c|c|c|c|c|c|c|}
\hline \multirow[b]{3}{*}{$\mathrm{n}$} & \multirow[b]{3}{*}{$\mathrm{q}$} & & \multicolumn{12}{|c|}{ True herding $\delta$ (in percent) } \\
\hline & & & \multicolumn{3}{|c|}{0.0} & \multicolumn{3}{|c|}{5.0} & \multicolumn{3}{|c|}{15.0} & \multicolumn{3}{|c|}{30.0} \\
\hline & & & $H_{|1|}$ & $\mathbb{H}_{2}$ & $H_{2}$ & $H_{|1|}$ & $\mathbb{H}_{2}$ & $H_{2}$ & $H_{|1|}$ & $\mathbb{H}_{2}$ & $H_{2}$ & $H_{|1|}$ & $\mathbb{H}_{2}$ & $H_{2}$ \\
\hline \multirow[t]{3}{*}{5} & 20 & power $95 \%$ & 5.2 & 8.6 & 32.1 & 4.8 & 7.0 & 31.3 & 14.5 & 10.0 & 52.5 & 95.3 & 93.0 & 99.8 \\
\hline & 100 & power $95 \%$ & 5.0 & 6.1 & 33.1 & 5.0 & 4.9 & 33.9 & 66.4 & 64.6 & 93.2 & 100.0 & 100.0 & 100.0 \\
\hline & 1000 & power $95 \%$ & 5.2 & 5.2 & 32.5 & 14.5 & 14.7 & 51.8 & 100.0 & 100.0 & 100.0 & 100.0 & 100.0 & 100.0 \\
\hline \multirow[t]{3}{*}{20} & 20 & power $95 \%$ & 5.9 & 10.2 & 34.0 & 6.5 & 5.6 & 36.4 & 90.9 & 86.4 & 99.4 & 100.0 & 100.0 & $\overline{100.0}$ \\
\hline & 100 & power $95 \%$ & 4.9 & 6.0 & 32.8 & 19.3 & 16.6 & 59.5 & 100.0 & 100.0 & 100.0 & 100.0 & 100.0 & 100.0 \\
\hline & 1000 & power $95 \%$ & 5.2 & 5.1 & 32.6 & 95.7 & 97.1 & 99.8 & 100.0 & 100.0 & 100.0 & 100.0 & 100.0 & 100.0 \\
\hline \multirow[t]{3}{*}{50} & 20 & power $95 \%$ & 5.8 & 10.8 & 34.2 & 15.8 & 9.6 & 55.9 & 100.0 & 99.9 & 100.0 & 100.0 & 100.0 & 100.0 \\
\hline & 100 & power $95 \%$ & 5.1 & 6.7 & 33.4 & 75.0 & 73.7 & 96.3 & 100.0 & 100.0 & 100.0 & 100.0 & 100.0 & 100.0 \\
\hline & 1000 & power $95 \%$ & 4.8 & 5.1 & 32.1 & 100.0 & 100.0 & 100.0 & 100.0 & 100.0 & 100.0 & 100.0 & 100.0 & 100.0 \\
\hline
\end{tabular}

Notes: This table reports the power at $95 \%$ confidence level of the test with the null hypothesis of no herding or $\delta=0$. All tests are t-tests applied to $H_{|1|}, \mathbb{H}_{2}$ and $H_{2}$. Monte Carlo simulation study includes 10,000 repetitions for each parameter combination. Parameter $\pi$ is set to 0.5 in all simulations. 
Table 5: Herding and trading intensity (aggregated)

\begin{tabular}{|c|c|c|c|c|c|}
\hline FM trading & $H_{|1|}$ & $\mathrm{H}_{2}$ & $\frac{H_{2}-H_{|1|}}{H_{2}}$ & Number of stock-periods & Average number of trades \\
\hline \multirow[t]{2}{*}{$n \geq 3$} & 0.0443 & 0.1597 & \multirow[t]{2}{*}{$72 \%$} & \multirow[t]{2}{*}{1865} & \multirow[t]{2}{*}{10.2} \\
\hline & $(0.0032)$ & $(0.0072)$ & & & \\
\hline \multirow[t]{2}{*}{$n \geq 5$} & 0.0477 & 0.1532 & \multirow[t]{2}{*}{$69 \%$} & \multirow[t]{2}{*}{1245} & \multirow[t]{2}{*}{13.6} \\
\hline & $(0.0035)$ & $(0.0064)$ & & & \\
\hline \multirow[t]{2}{*}{$n \geq 10$} & 0.0477 & 0.1404 & \multirow[t]{2}{*}{$66 \%$} & \multirow[t]{2}{*}{790} & \multirow[t]{2}{*}{17.7} \\
\hline & $(0.0040)$ & $(0.0065)$ & & & \\
\hline \multirow[t]{2}{*}{$n \geq 15$} & 0.0506 & 0.1417 & \multirow[t]{2}{*}{$64 \%$} & \multirow[t]{2}{*}{587} & \multirow[t]{2}{*}{19.6} \\
\hline & $(0.0045)$ & $(0.0073)$ & & & \\
\hline \multirow[t]{2}{*}{$n \geq 20$} & 0.0577 & 0.1471 & \multirow[t]{2}{*}{$61 \%$} & \multirow[t]{2}{*}{288} & \multirow[t]{2}{*}{22.2} \\
\hline & $(0.0064)$ & $(0.0095)$ & & & \\
\hline \multirow[t]{2}{*}{$n \geq 25$} & 0.0788 & 0.1734 & \multirow[t]{2}{*}{$55 \%$} & \multirow[t]{2}{*}{39} & \multirow[t]{2}{*}{25.7} \\
\hline & $(0.0190)$ & $(0.0224)$ & & & \\
\hline Mean of estimate & 0.0545 & 0.1526 & \multirow[t]{3}{*}{$64 \%$} & \multirow[t]{3}{*}{802} & \multirow[t]{3}{*}{18.2} \\
\hline Stddev of estimate & 0.0127 & 0.0125 & & & \\
\hline Relative Stddev & 0.2339 & 0.0820 & & & \\
\hline
\end{tabular}

Notes: The top part of this table reports herding measures $H_{|1|}$ and $H_{2}$ for Germany for various minimum thresholds for the number of transactions per stock. Corresponding standard errors are given in parentheses below the estimates. The relative bias, number of stock-periods and average number of trades per stock in each class are also reported. The bottom part of the table presents means of the estimated parameters, the relative bias, number of stock-periods and average number of trades per stock. The last two rows report the standard deviation of the class estimates in absolute terms as well as relative to the mean estimate.

Table 6: Herding and trading intensity (sub-samples)

\begin{tabular}{|l|r|r|r|r|r|}
\hline \hline FM trading & $H_{|1|}$ & $H_{2}$ & $\frac{H_{2}-H_{|1|}}{H_{2}}$ & Number of stock-periods & Average number of trades \\
\hline \hline $3 \leq n \leq 4$ & 0.0375 & 0.1720 & $78 \%$ & 620 & 3.4 \\
$5 \leq n \leq 9$ & $(0.0064)$ & $(0.0165)$ & & & \\
& 0.0476 & 0.1733 & $73 \%$ & 455 & \\
$10 \leq n \leq 14$ & $(0.0068)$ & $(0.0125)$ & & & 12.4 \\
& 0.0393 & 0.1364 & $71 \%$ & 203 & 17.2 \\
$15 \leq n \leq 19$ & $(0.0081)$ & $(0.0144)$ & & & \\
& 0.0438 & 0.1363 & $68 \%$ & 299 & 21.7 \\
$20 \leq n \leq 24$ & $(0.0064)$ & $(0.0111)$ & & & \\
& 0.0544 & 0.1426 & $62 \%$ & 249 & \\
$n \geq 25$ & $(0.0067)$ & $(0.0105)$ & & 39 & \\
& 0.0788 & 0.1734 & $55 \%$ & & \\
\hline \hline
\end{tabular}

Notes: This table reports herding measures $H_{|1|}$ and $H_{2}$ for Germany for various minimum thresholds for the number of transactions per stock. Corresponding standard errors are given in parentheses below the estimates. The relative bias, number of stock-periods and average number of trades per stock in each class are also reported. 
Table 7: Herding and stock size

\begin{tabular}{|c|c|c|c|c|c|}
\hline Market cap quintile & $H_{|1|}$ & $H_{2}$ & $\frac{H_{2}-H_{|1|}}{H_{2}}$ & Number of stock-periods & Average number of trades \\
\hline 1 (largest stocks) & $\begin{array}{r}0.0691 \\
(0.0112)\end{array}$ & $\begin{array}{r}0.1625 \\
(0.0158)\end{array}$ & $57 \%$ & 108 & 19.7 \\
\hline 2 & $\begin{array}{r}0.0468 \\
(0.0093)\end{array}$ & $\begin{array}{r}0.1371 \\
(0.0157)\end{array}$ & $66 \%$ & 137 & 20.0 \\
\hline 3 & $\begin{array}{r}0.0319 \\
(0.0081)\end{array}$ & $\begin{array}{r}0.1239 \\
(0.0188)\end{array}$ & $74 \%$ & 220 & 16.3 \\
\hline 4 & $\begin{array}{r}0.0453 \\
(0.0059)\end{array}$ & $\begin{array}{r}0.1565 \\
(0.0132)\end{array}$ & $71 \%$ & 492 & 10.6 \\
\hline 5 (smallest stocks) & $\begin{array}{r}0.0434 \\
(0.0050)\end{array}$ & $\begin{array}{r}0.1715 \\
(0.0113)\end{array}$ & $75 \%$ & 908 & 5.9 \\
\hline
\end{tabular}

Notes: This table reports herding measures $H_{|1|}$ and $H_{2}$ for Germany for sub-samples of stocks according to market capitalization. Total market capitalization of all stocks is split into quintiles, with stocks in quintile 1 having the largest market cap and stocks in quintile 5 having the smallest market cap. The reference year for classification was 2005. Corresponding standard errors are given in parentheses below the estimates. The relative bias, number of stock-periods and average number of trades per stock in each sub-sample are also reported.

Table 8: Herding in sub-periods

\begin{tabular}{|r|r|r|r|r|r|}
\hline \hline Year & $H_{|1|}$ & $H_{2}$ & $\frac{H_{2}-H_{|1|}}{H_{2}}$ & Number of stock-periods & Average number of trades \\
\hline \hline 1998 & 0.0474 & 0.1690 & $72 \%$ & 164 & 9.4 \\
& $(0.0112)$ & $(0.0240)$ & & & 10.2 \\
1999 & 0.0379 & 0.1534 & $75 \%$ & 233 & \\
& $(0.0088)$ & $(0.0215)$ & & & \\
2000 & 0.0563 & 0.1875 & $70 \%$ & 275 & 10.8 \\
& $(0.0084)$ & $(0.0170)$ & & & \\
2001 & 0.0740 & 0.2026 & $63 \%$ & 271 & 11.0 \\
& $(0.0087)$ & $(0.0160)$ & & & \\
2002 & 0.0215 & 0.0871 & $75 \%$ & 273 & \\
& $(0.0075)$ & $(0.0289)$ & & & \\
2003 & 0.0475 & 0.1681 & $72 \%$ & & \\
& $(0.0079)$ & $(0.0161)$ & & & \\
2004 & 0.0301 & 0.1328 & $77 \%$ & & \\
& $(0.0071)$ & $(0.0197)$ & & & \\
\hline \hline
\end{tabular}

Notes: This table reports herding measures $H_{|1|}$ and $H_{2}$ for Germany for sub-periods (years). Corresponding standard errors are given in parentheses below the estimates. The relative bias, number of stock-periods and average number of trades per stock in each sub-sample are also reported. 
Table 9: Analysis of the difference between $H_{2}$ and $H_{|1|}$

\begin{tabular}{|c|c|c|c|c|}
\hline & $\begin{array}{l}\text { Trading intensity } \\
\text { (aggregated) }\end{array}$ & $\begin{array}{l}\text { Trading intensity } \\
\text { (sub-samples) }\end{array}$ & Size & Years \\
\hline $\begin{array}{l}\text { A. Regression Analysis } \\
\text { Mean Dependent Variable } \\
(\mathrm{H} 2-\mathrm{H} 1)\end{array}$ & 0.0981 & 0.1054 & 0.1030 & 0.1163 \\
\hline Intercept & $\begin{array}{l}0.0469 \\
(0.0118)\end{array}$ & $\begin{array}{l}0.0424 \\
(0.0061)\end{array}$ & $\begin{array}{l}0.0782 \\
(0.0102)\end{array}$ & $\begin{array}{l}0.0744 \\
(0.0407)\end{array}$ \\
\hline Mean no. of trades per stock & $\begin{array}{l}-0.0009 \\
(0.0007)\end{array}$ & $\begin{array}{l}-0.0013 \\
(0.0001)\end{array}$ & $\begin{array}{l}-0.0009 \\
(0.0005)\end{array}$ & $\begin{array}{l}-0.0050 \\
(0.0036)\end{array}$ \\
\hline $\mathrm{H} 2$ & $\begin{array}{l}0.4140 \\
(0.0437)\end{array}$ & $\begin{array}{l}0.4815 \\
(0.0314)\end{array}$ & $\begin{array}{l}0.1841 \\
(0.041)\end{array}$ & $\begin{array}{l}0.5611 \\
(0.0695)\end{array}$ \\
\hline No. of stock-periods & $\begin{array}{l}0.000006 \\
(0.000006)\end{array}$ & $\begin{array}{l}0.000020 \\
(0.000006)\end{array}$ & $\begin{array}{l}0.000026 \\
(0.000009)\end{array}$ & $\begin{array}{l}0.000001 \\
(0.000045)\end{array}$ \\
\hline $\begin{array}{l}\text { No. of Observations } \\
\text { R-Square }\end{array}$ & $\begin{array}{l}6 \\
0.9980 \\
\end{array}$ & $\begin{array}{l}6 \\
0.9983 \\
\end{array}$ & $\begin{array}{l}5 \\
0.9986 \\
\end{array}$ & $\begin{array}{l}7 \\
0.9610 \\
\end{array}$ \\
\hline $\begin{array}{l}\text { B. Correlation Analysis } \\
\text { Spearman Rank Correlation } \\
\text { Coefficient } \\
\text { Prob(Zero Correlation) }\end{array}$ & $\begin{array}{l}0.0857 \\
0.8717 \\
\end{array}$ & $\begin{array}{l}0.4857 \\
0.3287 \\
\end{array}$ & $\begin{array}{l}0.5571 \\
0.3293 \\
\end{array}$ & $\begin{array}{l}0.9643 \\
0.0005 \\
\end{array}$ \\
\hline
\end{tabular}

Notes: A. Results from OLS regression of difference in herding statistics $\left(H_{|1|}-H_{2}\right)$ in tables 5 to 8 on intercept, average number of trades in sub-groups, value of $\mathrm{H}_{2}$ and number of stock-periods in sub-group. Standard errors are given in parentheses. B. Rank correlation analysis of the sub-groups with respect to $H_{|1|}$ and $H_{2}$. 
Figure 1: Expected $H_{|1|}^{q s}$ statistic and components

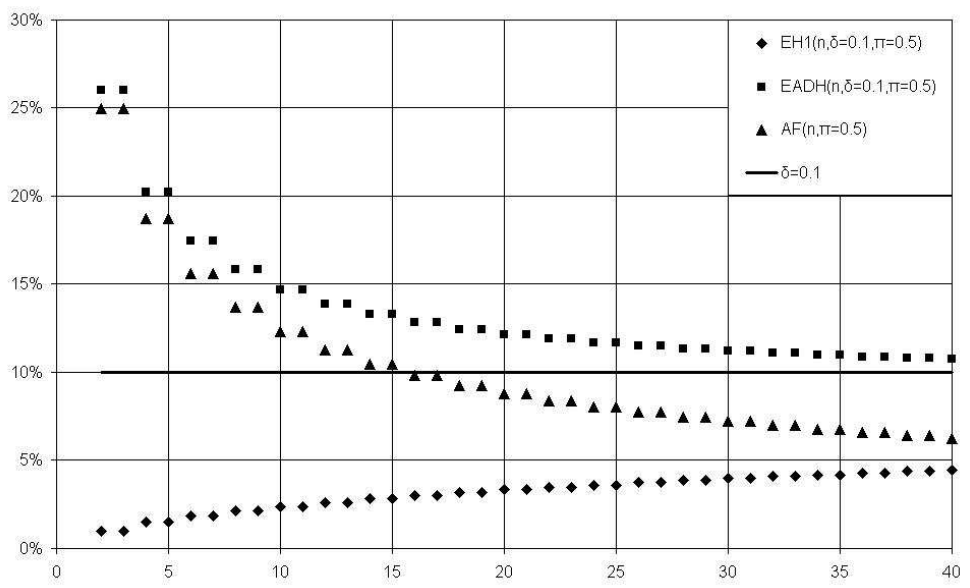

Notes: The figure shows (in percentages) a stock's expected $H_{|1|}$ measure (EH1) and its two components, the expected absolute dispersion (EADH) and the adjustment factor (AF) as functions of the number of trades in the stock. It also shows the true underlying herding parameter of $10 \%$. See appendix 5 for information on calculations and parameter inputs.

Figure 2: Expected $H_{|1|}^{q s}$ statistics and true herding parameters

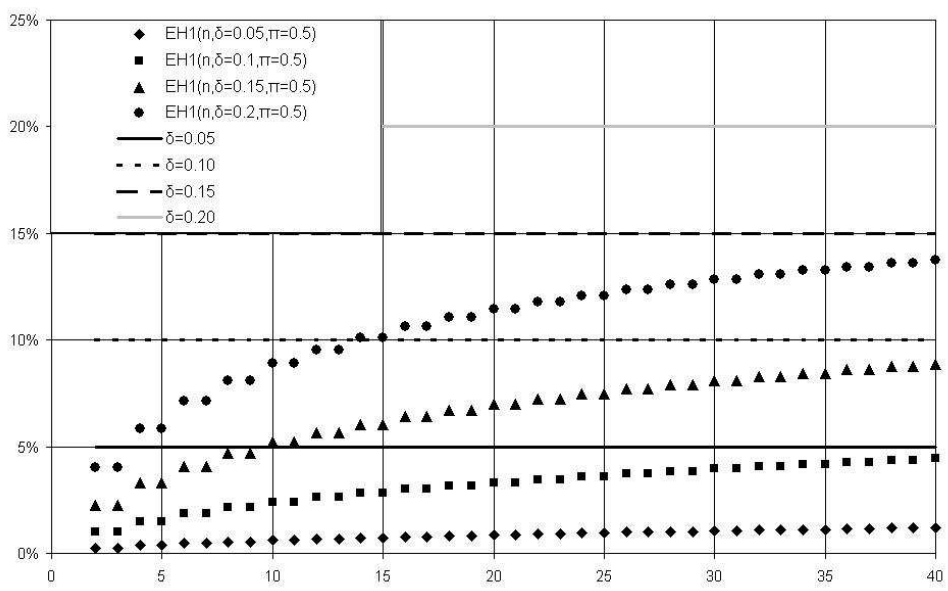

Notes: The figure shows (in percentages) the expected $H_{|1|}$ measure (EH1) for various levels of true herding $(\delta)$ as functions of the number of trades in the stocks, as well as the levels themselves. See appendix 5 for information on calculations and parameter inputs. 
Figure 3: Mean Square Errors for $H_{|1|}$ and $H_{2}$
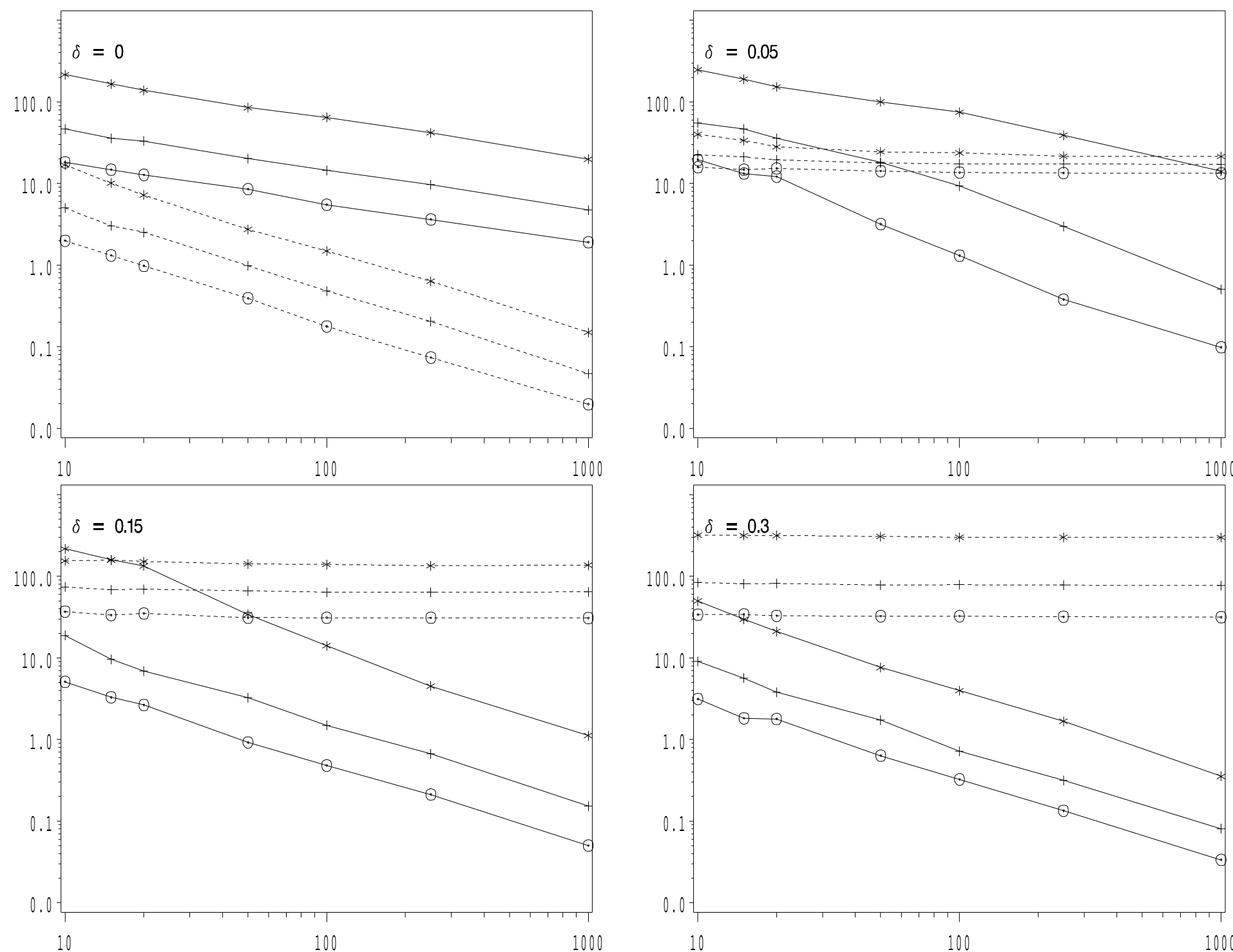

Notes: The graph shows the mean square error for $H_{2}$ (the solid lines) and $H_{|1|}$ (the dashed lines) on the vertical axis with number of observations on the horizontal. We apply a log-log transformation to the axis. Symbols indicate the number of portfolio managers trading at each observations: Asterisk $(*) \mathrm{n}=5$, plus $(+) \mathrm{n}=20$, circle with $\operatorname{dot}(\odot) \mathrm{n}=50$. True herding parameter $\delta$ varies from 0 (top left), 0.05 (top right), 0.15 (bottom left) to 0.30 (bottom right). Monte Carlo simulation study includes 10,000 repetitions for each parameter combination. Parameter $\pi$ is set to 0.5 in all simulations. 
Figure 4: Statistical power of $H_{|1|}$ and $\mathbb{H}_{2}$
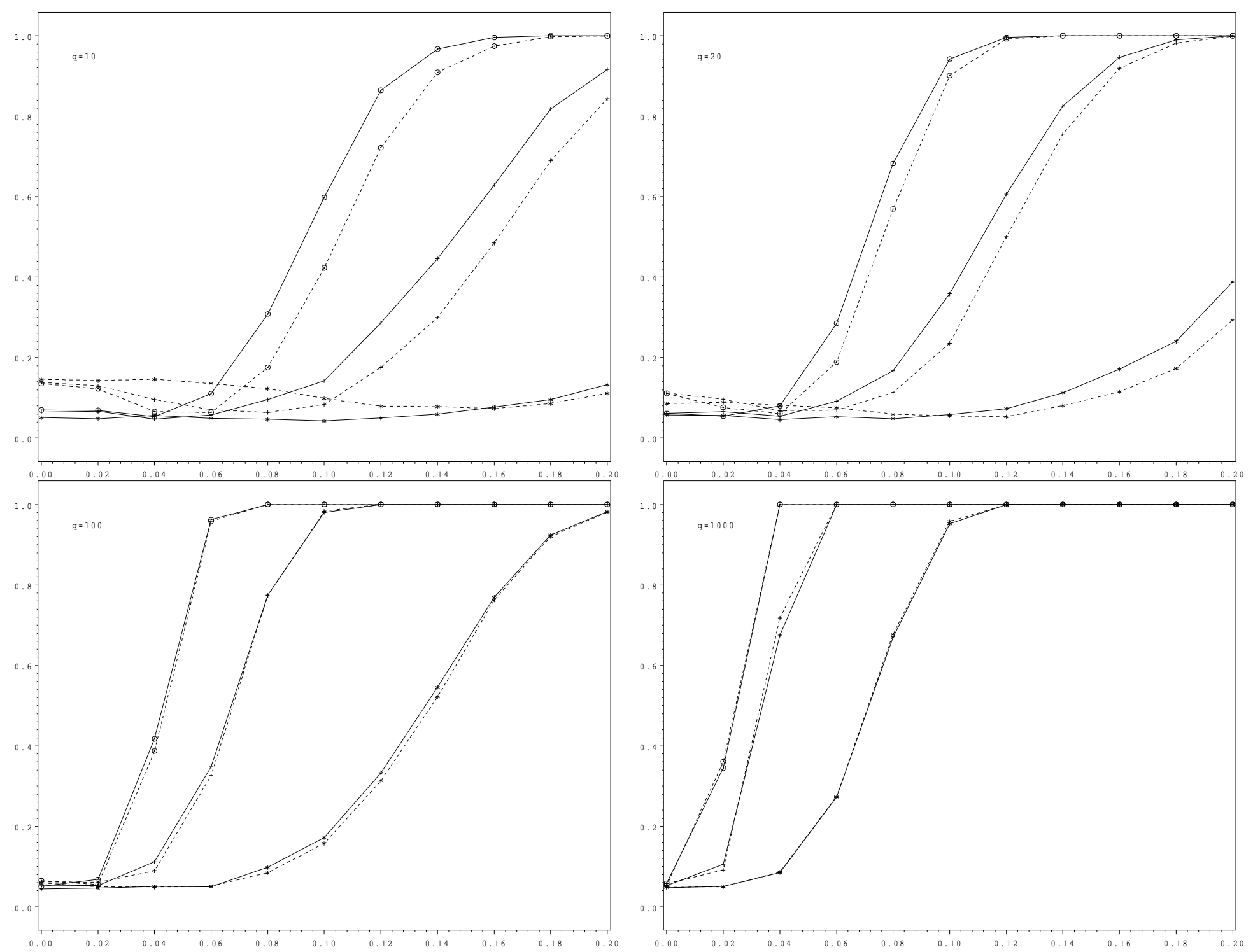

Notes: The graph above displays the power curve for the test of no herding at a $95 \%$ confidence level. $\delta$ is on the horizontal axis, whereas the probability of rejection of the null of $\delta=0$ is on the vertical axis. One can distinguish the results using $H_{|1|}$ (the solid black lines) and $\mathbb{H}_{2}$ (the dashed gray lines). Symbols indicate the number of portfolio managers trading at each observation: Asterisk $(*) \mathrm{n}=5$, plus $(+) \mathrm{n}=20$, circle with $\operatorname{dot}(\odot) \mathrm{n}=50$. The number of observations $\mathrm{q}$ increases from top left $(\mathrm{q}=10)$ to bottom right $(\mathrm{q}=1000)$ and is shown at the head of each panel. Monte Carlo simulation study includes 10,000 repetitions for each parameter combination. Parameter $\pi$ is set to 0.5 in all simulations. 